\title{
Mortality and functional outcome after surgical evacuation of traumatic acute subdural hematomas in octa- and nonagenarians
}

\author{
Alexander Younsi ${ }^{1}$ D $\cdot$ Jessica Fischer ${ }^{1} \cdot$ Cleo Habel $^{1} \cdot$ Lennart Riemann $^{1} \cdot$ Moritz Scherer $^{1} \cdot$ Andreas Unterberg $^{1}$. \\ Klaus Zweckberger ${ }^{1}$
}

Received: 9 March 2020 / Accepted: 15 June 2020 / Published online: 27 June 2020

(c) The Author(s) 2020

\begin{abstract}
Purpose The incidence of acute subdural hematomas (aSDH) is rising. However, beneficial effects of surgery for the oldest aSDH patients remain unclear. We hence describe the postoperative outcome of octa- and nonagenarians with aSDH in comparison to a younger patient cohort.

Methods Patients aged $\geq 80$ years surgically treated for traumatic aSDH at a single institution between 2006 and 2016 were retrospectively reviewed. Clinical and imaging variables were assessed, and univariate analysis was performed to identify factors predicting outcome at discharge. Results were compared to a cohort of younger aSDH patients and statistical analysis was performed. Long-term outcome was prospectively evaluated with the GOSE and QOLIBRI.

Results $27 \mathrm{aSDH}$ patients aged $\geq 80$ years were identified. On admission, $41 \%$ were in a comatose state and in-hospital mortality was $33 \%$. At discharge, $22 \%$ had a favorable outcome (GOS 4+5). In univariate statistical analysis, better neurological status (GCS > 8), $\leq 1$ comorbidity and smaller aSDH volumes were significant predictors for a favorable outcome. Comparison to 27 younger aSDH patients revealed significant differences in the prevalence of comorbidities and antithrombotics. At long-term follow-up, quality of life of aSDH patients was reduced (median QOLIBRI 54\%).

Conclusion Outcome after surgical treatment of aSDH in octa- and nonagenarians is not detrimental per se. Predictors for a favorable outcome are a non-comatose state on admission (GCS $>8$ ), $\leq 1$ preexisting comorbidity and a lower aSDH volume in patients aged $\geq 80$ years. In individual patients, surgical evacuation of aSDH might remain a treatment option even in high ages.
\end{abstract}

Keywords TBI · Acute subdural hematoma - Surgical evacuation · Elderly patients · Octogenarians · Quality of life · Outcome

\section{Background}

Traumatic brain injuries represent the leading cause of death and disability in patients aged $<45$ years, $[1,2]$ and in this heterogenous field, acute subdural hematoma (aSDH) is considered the most lethal injury [3]. However, demographic studies indicate senescence of the population; while people aged $>65$ years accounted for $22 \%$ of the total population in 2018 , they might represent one third of the total population by 2040 [4]. Accordingly, the age of patients diagnosed with

Alexander Younsi

alexander.younsi@med.uni-heidelberg.de

1 Department of Neurosurgery, University Hospital Heidelberg, University of Heidelberg, INF 400,

69120 Heidelberg, Germany traumatic brain injury (TBI) is increasing [5]. Considering the extended life expectancy with increasing frailty, comorbidities and rate of antithrombotic drug use on the one hand and the growing desire for mobility and autonomy of the older population on the other hand, the incidence of subdural hematomas in the elderly will be a growing problem, encompassing medical, social and financial domains [6].

Nevertheless, treatment decisions for aSDH are mainly based on studies performed on younger populations, disregarding comorbidities and the use of antithrombotic drugs in elderly patients. Moreover, data pertaining neurological outcome in aSDH patients aged $\geq 80$ years is still scarce and to date, only two studies have addressed this important topic $[7,8]$. This poses new challenges to physicians treating aSDH because well-defined outcome metrics and risk factors 
for younger aSDH patients do not necessarily apply for this older patient population [7].

Even though improvements in emergency care, neurointensive monitoring and surgical techniques have been made in the past decades, recently reported mortality rates for aSDH in the general population still range from $14 \%$ in mild traumatic brain injury to $100 \%$ in patients with low Glasgow Coma Scale (GCS) scores [9-14], leaving aSDH as one of the unsolved problems in neuro-traumatology.

Moreover, reported outcomes after surgical treatment of aSDH vary considerably with functional recovery being observed in $19-91 \%$ of cases even in younger patients [10, 15-17], while data on quality of life after aSDH surgery is generally lacking.

Patient age, pupillary asymmetry and unresponsiveness to light, low GCS scores [18, 19], postoperative seizures, time elapsed until treatment as well as large hematoma volume and midline shift have been described to negatively influence prognosis [15, 16, 20-22]. Unfortunately, most volumetric studies of aSDH date back to the 1990s and lack state-of-the art hematoma segmentation, which weakens these findings [20, 23, 24].

In this light, the decision to perform surgical aSDH evacuation especially in octo- and nonagenarians often remains challenging. With our current study, we, therefore, aimed to describe the clinical course and postoperative outcome of a cohort of the oldest ( $\geq 80$ years), surgically treated aSDH patients in comparison to a younger patient cohort, incorporating state-of-the art segmentation algorithms for volumetric aSDH analysis and including data on long-term quality of life.

\section{Methods}

\section{Study design}

We performed a single center, retrospective study with an additional prospective long-term follow-up analysis. The study was approved by the local ethical committee of our university in conformance to the Declaration of Helsinki and written informed consent for the participation in the prospective outcome analysis was obtained from all included patients [25].

\section{Participants}

The patient data utilized in this study was derived from our institutions electronic hospital records. First, we identified all patients who were diagnosed with aSDH in the period between January 2006 and December 2016. Then, additional inclusion criteria (age $\geq 18$ years, aSDH as the main finding on pre-operative imaging, craniotomy or decompressive craniectomy as the surgical procedure for hematoma evacuation) as well as exclusion criteria (spontaneous occurrence of aSDH without a history of trauma, aSDH as a postsurgical complication, acute on chronic SDH, aSDH localized in the posterior fossa, conservative treatment of aSDH or the presence of life limiting comorbidities such as carcinoma) were applied. For further analysis, only the oldest aSDH patients (aged $\geq 80$ years) were selected. In an additional step, a group of randomly selected younger aSDH patients (age $<80$ years) was formed to compare findings between both age cohorts.

\section{Data collection}

The following clinical parameters were retrospectively reviewed for all patients: age, sex and injury mechanisms, the pupillary status, the clinical symptoms and the GCS on admission. Additionally, details of preexisting comorbidities, usage of antithrombotic drugs and their pre-surgical reversal as well as pre-and postoperative laboratory findings were collected.

For imaging analysis, radiological parameters were assessed on pre-operative computerized tomography (CT) scans. In addition, a cross slice segmentation of volumes was performed on axial CT planes for the supratentorial region using the Medical Imaging Interaction Toolkit (MITK Workbench 2016.11.0, www.Mitk.org), an open source software kit for medical image computation. Segments were traced manually or using a semi-automatic threshold-based regiongrowing tool. Labeled voxels from every applicable slice were added with the MITK image statistics application to yield volume measures in cubic millimeters.

To assess the surgical procedures and postoperative course, we reviewed the time from admission until surgery, the surgical approach, details of the intensive care unit (ICU) stay as well as intracranial pressure (ICP) monitoring and therapy. If available, radiological findings on postoperative CT scans were additionally assessed. However, postoperative CT scans were only performed when the neurological status of operated patients deteriorated or did not improve.

For outcome assessments, rates of surgical, non-surgical and overall complications as well as the rate of revision surgeries were calculated, and the modality of discharge was noted. Neurological outcome at discharge was evaluated with the GCS and Glasgow Outcome Scale (GOS). Hereby, a poor neurological outcome was defined as GOS 1-3 whereas a favorable outcome was defined as GOS 4-5.

\section{Prospective outcome measures}

For assessment of neurological outcome and quality of life at long-term follow-up, all patients were contacted by mail and the self-rated Quality of Life after Brain Injury questionnaire 
(QOLIBRI) [26] as well as the Extended Glasgow outcome scale (GOSE) [27] were obtained and supplemented by a telephone interview. We defined a QOLIBRI total score $<65 \%$ as an indicator for low or impaired health-related quality of life and GOSE scores of 1-4 as an unfavorable outcome.

Patients who were deceased at the time of the prospective follow-up were excluded from the prospective outcome analysis. Patients who were unwilling or unable to participate in the prospective follow-up or cases in which no information on the current health status could be obtained were defined as lost to follow-up. Written informed consent for the participation in the prospective outcome analysis was obtained from all patients.

\section{Statistical analysis}

Data were analyzed using GraphPad Prism (version 7.0, GraphPad Software Inc.) and are given as median and interquartile range when not stated differently. In addition, univariate analysis was performed using an unpaired $t$ test for comparison of parametric values and Fisher's exact test for binary variables. To assess the impact of the variables, odds ratios with $95 \%$ confidence intervals were calculated. All tests were 2 -sided and a $p$ value $\leq 0.05$ was considered statistically significant.

\section{Results}

\section{Analysis of the oldest aSDH patients (aged $\geq 80$ years)}

Between January 2006 and December 2016, 27 patients aged $\geq 80$ years with aSDH who were treated at our institution and met the inclusion- and exclusion criteria were identified. Baseline characteristics and outcomes of this particular group of aSDH patients are presented in Table 1.

Median age among these 27 oldest aSDH patients was 84 years, ranging from 80 to 93 years, and 59\% were male. Preexisting comorbidities were present in $96 \%$ of cases, with arterial hypertension being the most common one $(81.5 \%)$. Seven old aSDH patients (25\%) had $\geq 5$ comorbidities. Most of the patients $(85 \%)$ were on antithrombotic therapy when admitted to our hospital. Anticoagulants like Phenprocoumon or antiplatelet agents like Aspirin were used most commonly (39\% each), but novel oral anticoagulants (NOACs) were already present in the remaining $18 \%$ of cases. Effects of Phenprocoumon were most often reversed with a 4-factor PCC (Prothrombin Complex Concentrate) (in 79\% of cases). All patients had suffered from head trauma prior to admission and a comatose status (defined as a GCS score $\leq 8$ ) as well as anisocoria on admission were seen in $41 \%$ of patients, respectively.
On pre-operative CT scans, left-sided aSDH was present in $44 \%$, right sided in $37 \%$ and aSDH on both sides was diagnosed in $19 \%$ of cases. A midline shift $>1 \mathrm{~cm}$ was detected in almost half of the patients $(44 \%)$ and median aSDH volume measured by volumetric analysis was $92 \mathrm{ml}$ (63-141 ml). Additional subarachnoid, intracranial and intraventricular hemorrhages were seen in $37 \%, 41 \%$ and $18 \%$ of patients, respectively. A representative pre- and postsurgical CT scan is shown in Fig. 1.

Median time elapsed between admission and surgical evacuation of the aSDH was $245 \mathrm{~min}$ (105-1138 min). All patients received a craniotomy for surgical evacuation with a median diameter of $7 \mathrm{~cm}(5-8 \mathrm{~cm})$, measured on postoperative CT scans. Subdural drains were inserted in half of all patients and ICP probes were implanted in $26 \%$. Postsurgically, $82 \%$ of patients were treated on the ICU, for a median of 5 days (3-6 days). Additional treatment for elevated ICP was implemented in $15 \%$ of cases during ICU treatment. Postoperative CT scans further revealed recurrent bleedings in 6 patients $(22 \%)$ of which four required revision surgeries. Secondary implantation of an external ventricular drain (EVD) and removal of a stuck subdural drain accounted for two other revision surgeries.

During the hospital stay, pneumonia was the most common non-surgical complication, occurring in one quarter of all patients aged $\geq 80$ years, followed by postoperative seizures in $22 \%$. Median duration of hospital stay was 6 (4-10 days). $63 \%$ of patients were transferred to another acute care hospital or rehabilitation center, while only one patient was discharged home. One third of the oldest aSDH patients deceased during the in-hospital stay. Only $22 \%$ of the patients were discharged with favorable outcomes (GOS $4-5$ ) and $78 \%$ had a poor recovery (GOS 1-3). Functional status on discharge, measured by the GOS score is shown in Fig. 2.

In univariate statistical analysis, we found $\leq 1$ preexisting comorbidities to be significantly associated with a favorable outcome at discharge $(p=0.05)$. Severity of the injury, defined as a GCS score of 3-8, higher aSDH volume and the necessity of ICU treatment were predictors for a poor functional recovery ( $p=0.05$ each). Surprisingly, the usage of antithrombotic drugs did not significantly influence outcome in the oldest aSDH patients. Neither did anisocoria or radiological signs of herniation correlate with an unfavorable outcome.

\section{Analysis of the younger aSDH patients}

Median age of the 27 randomly selected younger aSDH patients was 65 years, ranging from 19 to 75 years, 59\% were male and $78 \%$ reported preexisting comorbidities, whereof only 5 patients had $\geq 5$ comorbidities. $37 \%$ used antithrombotic 
Table 1 Characteristics and outcome of the oldest aSDH patients ( $\geq 80$ years)

\begin{tabular}{|c|c|c|c|c|c|}
\hline & All (no.[\%]) & $\begin{array}{l}\text { Favorable outcome } \\
\text { (no.[\%]) }\end{array}$ & $\begin{array}{l}\text { Unfavorable out- } \\
\text { come (no.[\%]) }\end{array}$ & OR $(95 \% \mathrm{CI})$ & $p$ value \\
\hline No. of patients & 27 & $6(22)$ & $21(78)$ & & \\
\hline \multicolumn{6}{|l|}{ Demographic factors } \\
\hline Median age in years (range) & $84(80-93)$ & $84(80-91)$ & $84(80-93)$ & & NS \\
\hline Male sex & $16(60)$ & $3(50)$ & $13(62)$ & & NS \\
\hline \multicolumn{6}{|l|}{ Comorbidities } \\
\hline Arterial hypertension & $22(81.5)$ & $5(83)$ & $17(81)$ & & NS \\
\hline Atrial fibrillation & $15(55.5)$ & $2(33)$ & $13(62)$ & & NS \\
\hline Comorbidities $\geq 5$ & $7(26)$ & $0(0)$ & $7(33)$ & & NS \\
\hline Comorbidities $\leq 1$ & $5(18.5)$ & $3(50)$ & $2(9.5)$ & $9.5(1.3-63.3)$ & $0.05^{\mathrm{a}}$ \\
\hline Anticoagulation & $23(85)$ & $4(67)$ & $19(90.5)$ & & NS \\
\hline \multicolumn{6}{|l|}{ Clinical presentation and imaging } \\
\hline Comatose on admission $(\mathrm{GCS}<8)$ & $11(41)$ & $0(0)$ & $11(52)$ & $0(0-0.7)$ & $0.05^{\mathrm{a}}$ \\
\hline Anisocoria & $11(41)$ & $1(17)$ & $10(48)$ & & NS \\
\hline Midlineshift $>1 \mathrm{~cm}$ & $12(44)$ & $1(17)$ & $11(52)$ & & NS \\
\hline Median volume of SDH in ml (IQR) & $92(63-141)$ & $67(24-91)$ & $118(71-149)$ & - & $0.05^{\mathrm{b}}$ \\
\hline Rad. Sign of herniation & $11(41)$ & $1(17)$ & $10(48)$ & & NS \\
\hline Reversal of anticoagulation & $14(52)$ & $3(50)$ & $11(52)$ & & NS \\
\hline \multicolumn{6}{|l|}{ Details on surgery } \\
\hline Median time to surgery in min (IQR) & $245(105-1138)$ & $485(270-488)$ & $208(97-2036)$ & & NS \\
\hline Median craniotomy diameter in $\mathrm{cm}$ (IQR) & $7(5-8)$ & $7(5-8)$ & $7(5-8)$ & & NS \\
\hline Subdural drains used & $15(55.5)$ & $4(67)$ & $11(52)$ & & NS \\
\hline ICP probe implanted & $7(26)$ & $1(17)$ & $6(29)$ & & NS \\
\hline Median duration of surgery in min (IQR) & $125(101-145)$ & $130(120-131)$ & $119(95.5-147)$ & & NS \\
\hline \multicolumn{6}{|l|}{ Postoperative course } \\
\hline ICU treatment & $22(81.5)$ & $3(50)$ & $19(90.5)$ & $0.1(0.01-0.8)$ & $0.05^{\mathrm{a}}$ \\
\hline ICP therapy & $4(15)$ & $0(0)$ & $4(19)$ & & NS \\
\hline Surgical complications & $7(26)$ & $0(0)$ & $7(33)$ & & NS \\
\hline Rebleeding & $6(22)$ & $0(0)$ & $6(29)$ & & NS \\
\hline Wound infection & $0(0)$ & $0(0)$ & $0(0)$ & & NS \\
\hline Others & $1(4)$ & $0(0)$ & $1(45)$ & & NS \\
\hline Revision surgery & $6(22)$ & $0(0)$ & $6(29)$ & & NS \\
\hline Non-surgical complications & $13(48)$ & $3(50)$ & $10(48)$ & & NS \\
\hline Remote cerebellar hemorrhage & $1(34)$ & $0(0)$ & $1(5)$ & & NS \\
\hline Cardiovascular & $3(11)$ & $0(0)$ & $3(14)$ & & NS \\
\hline Pneumonia & $7(26)$ & $3(50)$ & $4(19)$ & & NS \\
\hline Respiratory insufficiency & $2(7)$ & $0(0)$ & $2(10)$ & & NS \\
\hline Postoperative seizures & $6(22)$ & $1(17)$ & $5(24)$ & & NS \\
\hline Median hospital stay in days (IQR) & $6(4-10)$ & $8(5-10)$ & $5(4-10)$ & & NS \\
\hline \multicolumn{6}{|l|}{ Outcome at discharge } \\
\hline In-hospital mortality & $9(33)$ & $0(0)$ & $9(43)$ & & NS \\
\hline Discharged home & $1(4)$ & $1(17)$ & $0(0)$ & & NS \\
\hline Transferred to other hospital & $17(63)$ & $5(83)$ & $12(57)$ & & NS \\
\hline
\end{tabular}

Favorable outcome $=$ GOS $4+5$, Unfavorable outcome $=$ GOS $1-3$

GCS Glasgow coma scale, $S D H$ Subdural hematoma, ICP Intracranial pressure, ICU Intensive care unit, IQR Interquartile range, $O R$ Odds ratio; $C I$ Confidence interval, $N S$ not significant

$p>0.05$

${ }^{\mathrm{a}}$ Fisher exact test

${ }^{\mathrm{b}}$ Unpaired $t$ test 


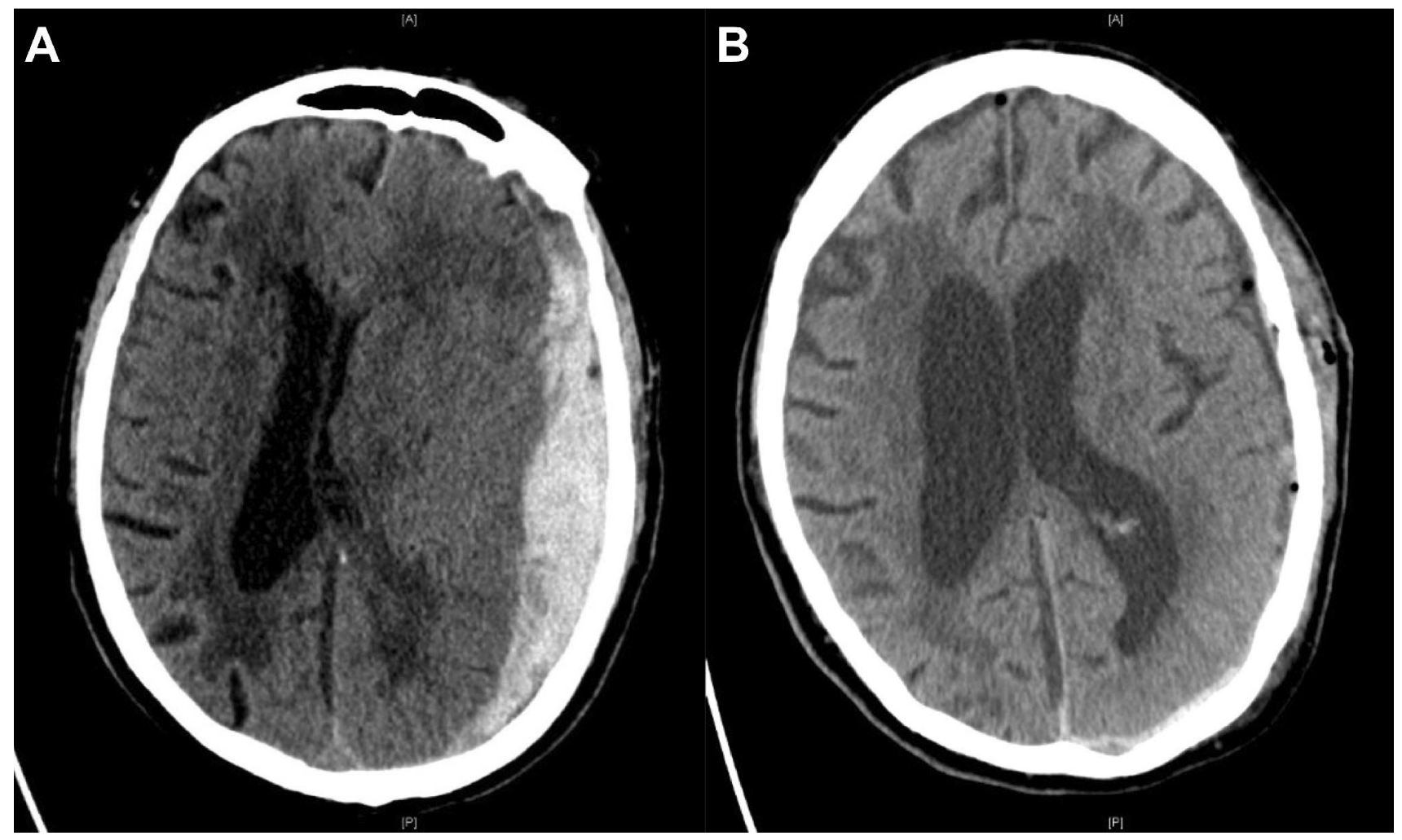

Fig. 1 a PreOP computed tomography (CT) of an 80-year-old patient showing a left-sided acute subdural hematoma (aSDH) with a max. diameter of $1.9 \mathrm{~cm}$ and approximately $1.3 \mathrm{~cm}$ midline shift (aSDH volume $=138 \mathrm{ml})$. b PostOP CT showing sufficient evacuation of the left-sided aSDH and declining midline shift. GOS score at discharge was 4

A

Oldest aSDH patients

B

Younger aSDH patients

GoS at discharge

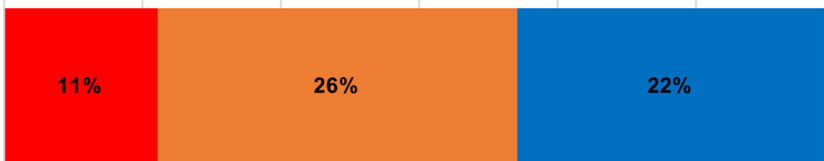

$15 \%$

$26 \%$

Fig. 2 Comparison of the GOS score on discharge for the oldest (age $\geqq 80$ years; a) and younger (b) patients, reflecting their functional status 
agents and in $80 \%$ of these patients, agents for reversal of the antithrombotic medication were pre-surgically administered.

Almost half of the patients of the younger group were comatose on admission (44\%). All patients received CT scans on admission, revealing right and left-sided aSDH with the same frequency. Median maximal diameter of the hemorrhages was $14 \mathrm{~mm}(11-19 \mathrm{~mm})$ and the calculated median hematoma volume was $71 \mathrm{ml}(52-105 \mathrm{ml})$. In addition, radiological signs of herniation were seen in 33\% and skull fractures were present in $44 \%$ of cases, while one third presented with additional subarachnoid or intracranial hemorrhages (30 and $33 \%$, respectively). For the younger aSDH patients, median time to surgery after admission was $237 \mathrm{~min}$ (118-571 $\mathrm{min}$ ). Surgical evacuation of the aSDH was performed via a craniotomy in $89 \%$ of cases and decompressive craniectomies where performed in the remaining $11 \%$. Subdural drainage systems were used in only $37 \%$ of cases and ICP probes were implanted in $26 \%$. After surgery, $70 \%$ of patients were treated on the neurosurgical ICU for a median of 6 days (2-11 days). Re-bleedings were seen on postoperative CT scans of four patients; one of them simultaneously developed problems with wound healing. Revision surgery was necessary in all of these patients. One additional case of wound healing disorder occurred but was treated conservatively. Median length of hospital stay for younger aSDH patients was 6 days (4-11 days) during which $37 \%$ developed pneumonia and $11 \%$ had postoperative seizures. The majority of the younger group was transferred to another health care facility (67\%) but $22 \%$ of the patients could be discharged home. At discharge, $44 \%$ showed functional recovery and 56\% had poor outcomes. Mortality in the group of the younger aSDH patients was $11 \%$.

In univariate statistical analysis, younger aSDH patients presenting with $\geq 5$ preexisting comorbidities had a significantly worse outcome at discharge $(p=0.04)$. Furthermore, a comatose state on admission $(p=0.001)$ as well as increased midline shift and higher volume of the aSDH ( $p=0.02$ each) were significantly associated with an unfavorable outcome. In contrast to the oldest aSDH patients, anisocoria and radiological signs of brain herniation were able to predict a poor outcome on discharge in the younger group $(p=0.008$ and $p=0.019$, respectively). As expected, the necessity of ICU treatment and ICP therapy was also significantly associated with an unfavorable outcome $(p=0.008$ and $p=0.0081$, respectively). Interestingly, faster time to surgery did not significantly improve outcome at discharge in the younger group, but patients with smaller craniotomy diameters recovered significantly better $(p=0.006)$.

\section{Comparison of the oldest and the younger aSDH patients and changes of clinical parameters over time}

Details of the comparison analysis of both age groups are presented in Table 2. Patients aged $\geq 80$ years had significantly more often arterial hypertension and atrial fibrillation compared to the younger group ( $p=0.01$, respectively). This correlated with a highly significant difference in the frequency of antithrombotic drug usage in the older patients $(p=0.0006)$. Parameters of clinical presentation and CT imaging on admission were comparable between the older and the younger group. Interestingly, time to surgery after admission was significantly shorter in the younger aSDH patients $(p=0.0336)$. Applied surgical methods and postsurgical care, however, did not differ significantly between both groups. Even though postsurgical seizures occurred twice as frequently in patients aged $\geq 80$ years then in the younger patients, a significant difference was not reached. More importantly, rate of complications and in-hospital mortality showed no significant difference between both age groups either. Similarly, although $44 \%$ of the younger and only $22 \%$ of the oldest aSDH patients showed a favorable outcome (GOS 4-5) on discharge, this difference remained insignificant.

Comparison of the first half of the study duration (January 2006 to June 2011, 66 months) to the second half (July 2011 to December 2016, 66 months) revealed similar findings for most of the clinical parameters in the aSDH patients overall. Relevant differences between the first and the second half of the study period could be observed concerning patient age $(68(48-74,5)$ years vs. $80(66-85)$ years, $p=0.057$ ), gender ( $78 \%$ male vs. $56 \%$ male, $p=0.2825$ ) and frequency of the usage of antithrombotic drugs (33\% vs. $67 \%, p=0.1306)$. Moreover, differences were present concerning the time to surgery after admission (436 (150-620) $\min$ vs. 234 (84-651 $\mathrm{min}$ ), $p=0.7372$ ), and the in-hospital mortality ( $11 \%$ vs. $24 \%, p=0.6652)$. However, none of those differences reached statistical significance in univariate analysis. Only the median volume of aSDHs was significantly different during the first half of the study compared to the second half (59 (39-88) vs. 92 (54-139) $\mathrm{ml}, p=0.0113)$.

\section{Prospective follow-up examination for health-related quality of life}

Of all aSDH patients in our study, 27 were deceased during the follow-up period and 18 were lost to follow-up. The remaining 9 patients were available for prospective followup examination after a median of 30 (21-40) months. Seven of those participants were from the younger age group and two were aged 82 and 83 years, respectively. The two patients aged $\geq 80$ years were admitted to the hospital with 
Table 2 Comparison of the oldest ( $\geq 80$ years) and younger aSDH patients

\begin{tabular}{|c|c|c|c|c|c|}
\hline & All (no.[\%]) & Oldest patients (no.[\%]) & Younger patients (no.[\%]) & OR $(95 \% \mathrm{CI})$ & $p$ value \\
\hline No. of patients & 54 & $27(50)$ & $27(50)$ & & \\
\hline \multicolumn{6}{|l|}{ Demographic factors } \\
\hline Median age in years (range) & $78(19-93)$ & $84(81-87)$ & $65(19-75)$ & & $>0.0001^{\mathrm{b}}$ \\
\hline Male sex & $32(59)$ & $16(59)$ & $16(59)$ & & NS \\
\hline \multicolumn{6}{|l|}{ Comorbidities } \\
\hline Arterial hypertension & $34(63)$ & $22(81.5)$ & $12(44)$ & $0.2(0.1-0.6)$ & $0.01^{\mathrm{a}}$ \\
\hline Atrial fibrillation & $20(37)$ & $15(55.5)$ & $5(18.5)$ & $0.2(0.1-0.6)$ & $0.01^{\mathrm{a}}$ \\
\hline Comorbidities $\geq 5$ & $12(22)$ & $7(26)$ & $5(18.5)$ & & NS \\
\hline Comorbidities $\leq 1$ & $19(35)$ & $5(18.5)$ & $14(52)$ & $4.7(1.4-14.8)$ & $0.02^{\mathrm{a}}$ \\
\hline Anticoagulation & $33(61)$ & $23(85)$ & $10(37)$ & $0.1(0.03-0.4)$ & $0.0006^{\mathrm{a}}$ \\
\hline \multicolumn{6}{|l|}{ Clinical presentation and imaging } \\
\hline Comatose on admission $(\mathrm{GCS}<8)$ & $23(43)$ & $11(41)$ & $12(44)$ & & NS \\
\hline Anisocoria & $18(33)$ & $11(41)$ & $7(26)$ & & NS \\
\hline Midlineshift $>1 \mathrm{~cm}$ & $24(44)$ & $12(44)$ & $12(44)$ & & NS \\
\hline Median volume of SDH in ml (IQR) & $71(52-105)$ & $92(63-141)$ & $71(52-105)$ & & NS \\
\hline Rad. Sign of herniation & $20(37)$ & $11(41)$ & $9(33)$ & & NS \\
\hline Reversal of anticoagulation & $22(41)$ & $14(52)$ & $8(30)$ & & NS \\
\hline \multicolumn{6}{|l|}{ Details on surgery } \\
\hline Median time to surgery in min (IQR) & $245(111-628)$ & $245(105-1138)$ & $237(118-571)$ & & $0.0336^{\mathrm{b}}$ \\
\hline Median craniotomy diameter in $\mathrm{cm}$ (IQR) & $7(5-8)$ & $7(5-8)$ & $7(5-8)$ & & NS \\
\hline Subdural drains used & $25(46)$ & $15(55.5)$ & $10(37)$ & & NS \\
\hline ICP probe implanted & $14(26)$ & $7(26)$ & $7(26)$ & & NS \\
\hline Median duration of surgery in min (IQR) & $118(90-141)$ & $125(101-145)$ & $115(83-133)$ & & NS \\
\hline \multicolumn{6}{|l|}{ Postoperative course } \\
\hline ICU treatment & $41(76)$ & $22(81.5)$ & $19(70)$ & & NS \\
\hline ICP therapy & $11(20)$ & $4(15)$ & $7(26)$ & & NS \\
\hline Surgical complications & $13(24)$ & $7(26)$ & $6(22)$ & & NS \\
\hline Rebleeding & $10(18.5)$ & $6(22)$ & $4(15)$ & & NS \\
\hline Wound infection & $2(4)$ & $0(0)$ & $2(7)$ & & NS \\
\hline Others & $1(2)$ & $1(4)$ & $0(0)$ & & NS \\
\hline Revision surgery & $11(20)$ & $6(22)$ & $5(18.5)$ & & NS \\
\hline Non-surgical complications & $26(48)$ & $13(48)$ & $13(48)$ & & NS \\
\hline Remote cerebellar hemorrhage & $1(2)$ & $1(4)$ & $0(0)$ & & NS \\
\hline Cardiovascular & $4(7)$ & $3(11)$ & $1(4)$ & & NS \\
\hline Pneumonia & $17(31.5)$ & $7(26)$ & $10(37)$ & & NS \\
\hline Respiratory insufficiency & $4(7)$ & $2(7)$ & $2(7)$ & & NS \\
\hline Postoperative seizures & $9(17)$ & $6(22)$ & $3(11)$ & & NS \\
\hline Median hospital stay in days (IQR) & $6(4-10)$ & $6(4-10)$ & $6(4-11)$ & & NS \\
\hline \multicolumn{6}{|l|}{ Outcome at discharge } \\
\hline GOS of $4-5$ at discharge & $18(33)$ & $6(22)$ & $12(44)$ & & NS \\
\hline In-hospital mortality & $12(22)$ & $9(33)$ & $3(11)$ & & NS \\
\hline Discharged home & $7(13)$ & $1(4)$ & $6(22)$ & & NS \\
\hline Transferred to other hospital & $35(65)$ & $17(63)$ & $18(67)$ & & NS \\
\hline
\end{tabular}

GCS Glasgow coma scale, GOS Glasgow outcome scale, SDH Subdural hematoma, ICP Intracranial pressure, ICU Intensive care unit, IQR Interquartile range, $O R$ Odds ratio; $C I$ Confidence interval, $N S$ not significant

$p>0.05$

${ }^{\mathrm{a}}$ Fisher exact test

${ }^{\mathrm{b}}$ Unpaired $t$ test 
only mild traumatic injury (GCS score 13-14) but left the hospital in a severely disabled state after aSDH evacuation (GOS 3 both). Nevertheless, they described upper moderate disability (GOSE 6) and upper good recovery (GOSE 8), respectively, at the time of follow-up. Assessment of health-related quality of life by the QOLIBRI questionnaire revealed scores of $40 \%$ and $56 \%$ for the two patients aged $\geq 80$ years, indicating impaired quality of life. Clinical parameters and quality of life scores of all prospectively analyzed patients are presented in Table 3 .

\section{Discussion}

\section{Mortality, functional outcome and quality of life after aSDH surgery in the elderly}

Sixty-seven percent of the patients aged 80 years or above surgically treated for traumatic aSDH in our study survived the in-hospital stay and the mortality rate for octa- and nonagenarians thus was only $33 \%$. In contrast to our findings, mortality rates of patients aged 60 or above reported by Jennet et al. in 1976 [16] or by Howard et al. in 1989 [20] were substantially higher, with up to $88 \%$ and $74 \%$, respectively. Moreover, the mortality rate of younger aSDH patients (18-40 years) reported by Howard et al. was significantly lower with $18 \%$ compared to the older aSDH patients ( $\geq 65$ years) [20]. Since then, increasing age is considered to be an independent predictor for mortality after aSDH, which has also been confirmed in more recent publications $[10-12,28]$. While only $11 \%$ of the younger aSDH patients died in direct consequence of the hemorrhage in our study, the difference to the oldest patients did not reach statistical significance. Our results could, therefore, be interpreted as a trend towards decreased early mortality of elderly aSDH patients, similar to recent findings by Won et al. who reported a mortality rate of octogenarians of only $28 \%$, [8] These improvements in early survival of older patients after traumatic aSDH might reflect the advancements of surgical treatments and ICU care in the past decades.

Unfortunately, mortality after aSDH is not restricted to the in-hospital stay but rather continuing during the months after the injury. In a study from the 1990s, mortality during a 6 month follow-up period after aSDH was reported to be as high as 50\% [19]. In our study with a long followup period, a total of 15 additional aSDH patients had died (62.5\%) 30 (21-40) months after the injury. Of those, only four were of the younger age group (27\%) and $11(73 \%)$ had been $\geq 80$ years old when the aSDH had occurred. Higher mortality rates during follow-up in patients aged $\geq 80$ years could be regarded as a direct consequence of the advanced age, often accompanied by an increasing number of comorbidities, a higher incidence of medical complications or a greater usage of antithrombotic agents as seen in our study. In addition, decreasing numbers of intact neurons and greater exposure to repetitive insults over a lifetime [29] could be responsible for impaired repair capacity of brain damage in the elderly, leading to a stepwise increase in probability of poor outcome with increasing age [2,30].

In previous studies, functional recovery of aSDH patients aged $\geq 65$ years has been reported in only $9 \%$ of cases, [20] questioning the benefit of surgical evacuation of aSDH in the elderly. Non-age specific favorable outcomes were, however, seen in $19-32 \%$, [10, 15] increasing up to $91 \%$ in patients with admission GCS scores of 13-15 [17]. In our current study, we found a favorable outcome at discharge in $22 \%$ of the oldest aSDH patients, suggesting improved functional recovery in octo- and nonagenarians compared to older reports in the literature [8, 14]. More importantly, outcome at discharge was not significantly different between the young and the oldest aSDH patients. This might in part be related to the fact, that aSDH patients in our study were

Table 3 Details on clinical status, neurological outcome and QoL of aSDH patients who participated in the long-term follow-up examination

\begin{tabular}{lllllllll}
\hline Age (years) & $\begin{array}{l}\text { No. of } \\
\text { comorbidi- } \\
\text { ties }\end{array}$ & Anisocoria & General complications & $\begin{array}{l}\text { GCS on } \\
\text { admission }\end{array}$ & $\begin{array}{l}\text { GOS at } \\
\text { discharge }\end{array}$ & $\begin{array}{l}\text { GOS at } \\
\text { follow-up }\end{array}$ & $\begin{array}{l}\text { GOSE at follow-up } \\
\text { QOLIRBI } \\
\text { at follow- } \\
\text { up }\end{array}$ \\
\hline 37 & 0 & No & Pneumonia & 3 & 2 & 3 & Upper SD (4) & $40 \%$ \\
62 & 3 & No & None & 14 & 4 & 5 & Upper GR (8) & $58 \%$ \\
65 & 0 & No & Pneumonia & 3 & 3 & 5 & Upper GR (8) & $62 \%$ \\
67 & 4 & Yes & Pneumonia & 3 & 2 & 3 & Lower SD (3) & $54 \%$ \\
71 & 4 & No & Pneumonia & 13 & 4 & 5 & Lower GR (7) & $59 \%$ \\
71 & 3 & No & Pneumonia & 13 & 4 & 3 & Lower SD (3) & $40 \%$ \\
72 & 2 & Yes & Resp. Insufficiency & 3 & 2 & 3 & Lower SD (3) & $44 \%$ \\
82 & 4 & No & Seizure & 14 & 3 & 4 & Upper MD (6) & $40 \%$ \\
\hline 3 & 1 & Yes & None & 13 & 3 & 5 & Upper GR (8)
\end{tabular}

GCS Glasgow coma scale, GOS Glasgow outcome scale, GOSE Glasgow outcome scale extended, QOLIBRI Quality of life after brain injury, $G R$ Good recovery, $S D$ Severe disability, $M D$ Moderate disability 
mostly treated on our highly specialized neuro-intensive care unit with substantial experience in handling more severe and complex neurosurgical cases.

Although the rate of successful prospective follow-up achieved in our study was low (17\%), it revealed exemplary cases of long-term recovery after aSDH surgery in the elderly: two patients aged $\geq 80$ years who had both been discharged from the hospital in a severely disabled state (GOS 3) had GCS scores of 13 and 14 and showed good recovery (GOSE 6 and 8) at follow-up. On the other hand, quality of life measured by the QOLIBRI score was low or impaired $(<65 \%)$ in all aSDH patients who were available for follow-up in our study, including cases with good functional recovery (GOSE 7 and 8), although a significant correlation between QOLIBRI and GOSE scores for patients with traumatic brain injury has been reported in the literature [26]. It, therefore, seems necessary to evaluate healthrelated quality of life with corresponding measurements such as the QOLIBRI separately from functional recovery to better understand the overall outcome after surgical treatment in aSDH patients.

\section{Outcome prediction after aSDH surgery in octo- and nonagenarians}

Although comorbidities such as arterial hypertension or atrial fibrillation, correlating with a frequent usage of antithrombotic medication, were significantly more common in the oldest than in the younger aSDH patients, they did not individually predict an unfavorable outcome at discharge in our study. We assume that pre-surgical reversal of antithrombotic medication, interdisciplinary treatment on a specialized ICU and standardized treatment protocols may have reduced the risk for complications and (re)bleedings, and thus might play important roles in the improvement of survival of elderly aSDH patients $[8,22]$. However, the presence of fewer comorbidities was associated with a favorable outcome at discharge in patients aged 80 years or above whereas preexistence of $\geq 5$ comorbidities was linked to an unfavorable outcome in many patients in both age groups, suggesting that the sum of comorbidities and the resulting general health status are indeed able to influence outcome at discharge after surgical aSDH treatment.

The neurological status after injury, mostly reported as the GCS score at admission, has frequently been associated with functional outcome after aSDH surgery [3, 12]. Correspondingly, we were able to confirm a comatose status at admission, defined as a GCS score of 3-8, as a significant predictor for an unfavorable outcome at discharge in the young, but more importantly also in the oldest aSDH patients in our study. This is in accordance with findings of Won et al., who also confirmed the predictive value of the GCS for functional outcome at discharge in octo-and nonagenarians [8].

Interestingly, anisocoria and radiological signs of herniation were only found to be significant predictors for an unfavorable outcome at discharge in the group of younger aSDH patients in our study. In the elderly patients, less severe brain injury without clinical or radiological signs of herniation might have been sufficient to worsen results of the relatively broad outcome score GOS and might therefore have affected this finding. Nevertheless, pupillary abnormalities should be interpreted as signs of severe injury in all aSDH patients [12, $17,31]$. Similarly, a midline shift $>1 \mathrm{~cm}$ was only associated with an unfavorable outcome at discharge in the group of younger aSDH patients, suggesting that effects of brain atrophy and wider subdural spaces in patients aged $\geq 80$ years might have allowed for more midline shift without having the same impact on outcome.

\section{Value of volumetric aSDH analysis in outcome prognostication}

The association between aSDH volume and outcome was already analyzed in the 1980s and 1990s, [20, 23, 24] with volumes being manually calculated. Favorable outcomes were seen in patients with mean hematoma volumes of $31 \mathrm{ml}$ [23] $(<100 \mathrm{ml}[24])$ and poor recovery was associated with mean hematoma volumes of $104 \mathrm{ml}$ [23] (>100 ml [24]). Additionally, Howard et al. [20] described significant differences in mean volumes between patients aged over 65 years (mean $96.2 \pm 11.72 \mathrm{ml}$ ) and patients aged 18-40 years $(21.6 \pm 27.7 \mathrm{ml})$. Volumetric measurements of aSDH were already conducted in 2009, [31] using computer assisted analysis and volumes $<50 \mathrm{ml}$ were associated with higher rates of functional recovery (50\%) in comparison to larger bleedings ( $>50 \mathrm{ml}, 34 \%$ functional recovery).

A correlation between larger hematoma volume and worse outcome was also seen in our patient cohort. Patients aged $\geq 80$ years who had an unfavorable outcome showed almost twice the size of aSDH volumes than patients with a favorable outcome. This finding was also applicable for the younger aSDH cohort $(p=0.02)$.

Interestingly, the mean aSDH volume was greater in the elderly patient population compared to the younger patients without yielding statistical significance. Nevertheless, this finding might reflect the higher use of antithrombotic drugs in patients aged 80 years and above, making them prone to more extensive traumatic bleedings.

\section{Ethical considerations}

Our current results underline that while a chance for a good functional outcome exists and while the risk of mortality is reduced, surgical evacuation of traumatic aSDHs in 
octo- and nonagenarians is still leading to high rates of poor outcome and reduced quality of life - circumstances, under which many older patients might not want to further live their lives. The availability of a patient decree outlining the individual treatment choices and wishes should, therefore, always be inquired and in applicable cases, the decision to perform surgery should only be taken in consideration of the patients written will. In light of frequent preexisting conditions such as care dependency or dementia in the elderly population, the suspected will of the patient has to be respected even when no patient decree is existing or present and thus, her or his relatives should be consulted if possible.

\section{Limitations}

Several limitations of our study should be acknowledged. The analysis was performed at a single institution in a retrospective manner over a long period of time (11 years), limiting external validity and posing the risk of changes in the management of aSDH patients. However, comparison of clinical parameters between the first and the second half of the study period revealed no relevant significant differences over time. Nevertheless, the available patient cohort of aSDH patients aged $\geq 80$ years was small and the univariate statistical analysis therefore potentially underpowered. In addition, due to the limited number of eligible aSDH patients overall, mathematical matching of the oldest with the younger patients was not feasible and findings in octo- and nonagenerians were compared with randomly selected younger patients instead. Findings of the comparison between both groups have, therefore, to be interpreted with caution. Due to the small sample size, multivariate analysis was also not feasible, making it impossible to rule out that some variables are dependable in our study. Furthermore, we excluded patients in whom the decision to withhold surgical treatment was taken, hereby potentially biasing our results towards better outcomes. Additionally, an even smaller sample size of patients was available for follow-up analysis which limits the general applicability of our results on health-related quality of life. We also did not differentiate between patients undergoing rehabilitation, biasing outcome at follow-up. Broader prospective studies on long-term outcome of elderly aSDH patients with larger cohorts or national as well as international trauma registries are therefore needed to better understand risks and chances of surgical treatment in this patient subgroup.

\section{Conclusions}

Outcome after surgical treatment of aSDH in octa- and nonagenarians compared to a younger population is not detrimental per se. A lower general health status with more comorbidities as well as a higher usage of antithrombotic drugs represented the major differences between younger and the oldest (age $\geq 80$ years) aSDH patients in our study. Moreover, the presence of preexisting comorbidities, a more severe brain injury and a higher volume of the aSDH were associated with a worse outcome in patients aged $\geq 80$ years. In comparison to previously published studies, we found lower mortality (33\%) and increased functional recovery (22\%) rates as well as individual cases of upper moderate disability or upper good recovery in long-term follow-up in the oldest aSDH patients. Our findings suggest, that surgical evacuation of aSDH might be a possible treatment concept for patients even in high ages. Nevertheless, the sum of preexisting comorbidities, poor neurological admission scores and morphologic findings on CT scans should be taken into account and treatment decisions should only be made on an individualized basis, taking into the account the specific wishes of the affected patient.

Acknowledgements Open Access funding provided by Projekt DEAL. We thank Julia Mattern and Madlen Rädel for their help with this study.

Author contributions All authors contributed to the study conception and design. Material preparation, data collection and analysis were performed by AY, JF, CH and LR. The first draft of the manuscript was written by AY and JF and all authors commented on previous versions of the manuscript. All authors read and approved the final manuscript.

Funding No funding was received for this study.

\section{Compliance with ethical standards}

Conflicts of interest All authors state no conflict of interest.

Ethical approval The study was approved by the local ethical committee in conformance to the Declaration of Helsinki.

Consent to participate For the retrospective analysis in this study, no informed consent was required. Written informed consent was however obtained from all patients who participated in the prospective outcome analysis.

Open Access This article is licensed under a Creative Commons Attribution 4.0 International License, which permits use, sharing, adaptation, distribution and reproduction in any medium or format, as long as you give appropriate credit to the original author(s) and the source, provide a link to the Creative Commons licence, and indicate if changes were made. The images or other third party material in this article are included in the article's Creative Commons licence, unless indicated otherwise in a credit line to the material. If material is not included in the article's Creative Commons licence and your intended use is not permitted by statutory regulation or exceeds the permitted use, you will need to obtain permission directly from the copyright holder. To view a copy of this licence, visit http://creativecommons.org/licenses/by/4.0/. 


\section{References}

1. National center for injury prevention and control. Injury Fact Book. Atlanta: Centers for Disease Control and Prevention; 2001.

2. Hukkelhoven CWPM, Steyerberg EW, Rampen AJJ, Farace E, Habbema JDF, Marshall LF, et al. Patient age and outcome following severe traumatic brain injury: an analysis of 5600 patients. J Neurosurg. 2003;99:666-73.

3. Gennarelli TA, Spielman GM, Langfitt TW, Gildenberg PL, Harrington T, Jane JA, et al. (1982) Influence of the type of intracranial lesion on outcome from severe head injury. J Neurosurg 56:26-32. Available from: https://thejns.org/view/journals/j-neuro surg/56/1/article-p26.xml. Accessed 9 Mar 2020

4. Künftige Bevölkerungsentwicklung in Deutschland. Statistisches Bundesamt (Destatis) 2019. https://www.destatis.de/DE/Themen/ Gesellschaft-Umwelt/Bevoelkerung/Bevoelkerungsvorausberech nung/_inhalt.html;jsessionid=F174C59D50BDE9FECE035FCA9 F3E5361.internet8711\#sprg229086.Accessed 09 Mar 2020

5. Andriessen TMJC, Horn J, Franschman G, van der Naalt J, Haitsma I, Jacobs B, et al. (2011) Epidemiology, severity classification, and outcome of moderate and severe traumatic brain injury: a prospective multicenter study. J Neurotrauma 28:201931. Available from: https://www.ncbi.nlm.nih.gov/pubmed/21787 177 Accessed 2013 May 29

6. Steyerberg EW, Wiegers E, Sewalt C, Buki A, Citerio G, De Keyser V, et al. (2019) Case-mix, care pathways, and outcomes in patients with traumatic brain injury in CENTER-TBI: a European prospective, multicentre, longitudinal, cohort study. Lancet Neurol 18:923-34. Available from: https://linkinghub.elsevier.com/retri eve/pii/S1474442219302327. Accessed 9 Mar 2020

7. McGinity MJ, Michalek JE, Rodriguez JS, Floyd JR. (2017) Surgical evacuation of acute subdural hematoma in octogenarians: a ten-year experience from a single trauma center. Br J Neurosurg. Taylor and Francis 31:714-7. Available from: https://www.tandf online.com/doi/full/10.1080/02688697.2017.1341041 Accessed 2020 May 18

8. Won S-Y, Dubinski D, Brawanski N, Strzelczyk A, Seifert V, Freiman TM, et al. (2017) Significant increase in acute subdural hematoma in octo- and nonagenarians: surgical treatment, functional outcome, and predictors in this patient cohort. Neurosurg Focus. 43:E10. Available from: https://thejns.org/ doi/10.3171/2017.7.FOCUS17417https://www.ncbi.nlm.nih.gov/ pubmed/29088952. Accessed 9 Mar 2020

9. Ryan CG, Thompson RE, Temkin NR, Crane PK, Ellenbogen RG, Elmore JG. (2012) Acute traumatic subdural hematoma: current mortality and functional outcomes in adult patients at a Level I trauma center. J Trauma Acute Care Surg 73:1348-54. Available from: https://www.ncbi.nlm.nih.gov/pubmed/23117390. Accessed 9 Mar 2020

10. Leitgeb J, Mauritz W, Brazinova A, Janciak I, Majdan M, Wilbacher I, et al. (2012) Outcome after severe brain trauma due to acute subdural hematoma. J Neurosurg 117:324-33. Available from: https://www.ncbi.nlm.nih.gov/pubmed/22631691 Accessed 2017 Oct 15

11. Vilcinis R, Bunevicius A, Tamasauskas A. (2017) The Association of Surgical Method with Outcomes of Acute Subdural Hematoma Patients: Experience with 643 Consecutive Patients. World Neurosurg 101:335-42. Available from: https://www.ncbi.nlm.nih.gov/ pubmed/28216211 Accessed 2017 Oct 15

12. Fountain DM, Kolias AG, Lecky FE, Bouamra O, Lawrence T, Adams H, et al. (2017) Survival Trends After Surgery for Acute Subdural Hematoma in Adults Over a 20-year Period. Ann Surg. 265:590-6. Available from: https://www.ncbi.nlm.nih.gov/pubme d/27172128 Accessed 2017 Oct 15
13. Raj R, Mikkonen ED, Kivisaari R, Skrifvars MB, Korja M, Siironen J. (2016) Mortality in Elderly Patients Operated for an Acute Subdural Hematoma: A Surgical Case Series. World Neurosurg 88:592-7. Available from: https://www.ncbi.nlm.nih.gov/ pubmed/26548818 Accessed 2017 Oct 15

14. Taussky P, Hidalgo ET, Landolt H, Fandino J. (2012) Age and Salvageability: Analysis of Outcome of Patients Older than 65 Years Undergoing Craniotomy for Acute Traumatic Subdural Hematoma. World Neurosurg 78:306-11. Available from: https ://www.ncbi.nlm.nih.gov/pubmed/22120569 Accessed 2017 Oct 15

15. Wilberger JE, Harris M, Diamond DL. Acute subdural hematoma: morbidity, mortality, and operative timing. J Neurosurg. 1991;74:212-8.

16. Jennett B, Teasdale G, Braakman R, Minderhoud J, Knill-Jones R. (1976) Predicting outcome in individual patients after severe head injury. Lancet (London, England) 1:1031-4. Available from: https ://www.ncbi.nlm.nih.gov/pubmed/57446. Accessed 9 Mar 2020

17. Koç RK, Akdemir H, Oktem IS, Meral M, Menkü A. Acute subdural hematoma: outcome and outcome prediction. Neurosurg Rev. 1997;20:239-44.

18. Bartels RHMA, Meijer FJA, van der Hoeven H, Edwards M, Prokop M. Midline shift in relation to thickness of traumatic acute subdural hematoma predicts mortality. BMC Neurol. 2015;15:220.

19. Phuenpathom N, Choomuang M, Ratanalert S. Outcome and outcome prediction in acute subdural hematoma. Surg Neurol. 1993;40:22-5.

20. Howard MA, Gross AS, Dacey RG, Winn HR. Acute subdural hematomas: an age-dependent clinical entity. J Neurosurg. 1989;71:858-63.

21. Seelig JM, Becker DP, Miller JD, Greenberg RP, Ward JD, Choi SC. (1981) Traumatic acute subdural hematoma: major mortality reduction in comatose patients treated within four hours. N Engl J Med 304:1511-8. Available from: https://www.ncbi.nlm.nih.gov/ pubmed/7231489. Accessed 9 Mar 2020

22. Haselsberger K, Pucher R, Auer LM. (1988) Prognosis after acute subdural or epidural haemorrhage. Acta Neurochir (Wien). 90:111-6. Available from: https://www.ncbi.nlm.nih.gov/pubme $\mathrm{d} / 3354356$

23. Yanaka K, Kamezaki T, Yamada T, Takano S, Meguro K, Nose T. (1993) Acute subdural hematoma-prediction of outcome with a linear discriminant function. Neurol Med Chir (Tokyo) 33:552-8. Available from: https://www.ncbi.nlm.nih.gov/pubmed/7692328. Accessed 9 Mar 2020

24. Stone JL, Rifai MH, Sugar O, Lang RG, Oldershaw JB, Moody RA, Subdural hematomas I. Acute subdural hematoma: progress in definition, clinical pathology, and therapy. Surg Neurol. 1983;19:216-31.

25. World Medical Association. World Medical Association Declaration of Helsinki: ethical principles for medical research involving human subjects. JAMA. 2013;310:2191-4.

26. von Steinbüchel N, Wilson L, Gibbons H, Hawthorne G, Höfer S, Schmidt S, et al. (2010) Quality of Life after Brain Injury (QOLIBRI): scale validity and correlates of quality of life. J Neurotrauma 27:1157-65. Available from: https://www.ncbi.nlm.nih. gov/pubmed/20210602. Accessed 9 Mar 2020

27. Wilson JT, Pettigrew LE, Teasdale GM. (1998) Structured interviews for the Glasgow Outcome Scale and the extended Glasgow Outcome Scale: guidelines for their use. J Neurotrauma 15:57385. Available from: https://www.ncbi.nlm.nih.gov/pubmed/97262 57. Accessed 9 Mar 2020

28. Evans LR, Jones J, Lee HQ, Gantner D, Jaison A, Matthew J, et al. Prognosis of acute subdural hematoma in the elderly: a systematic review. J Neurotrauma. 2019;36:517-22. 
29. Peters R. (2006) Ageing and the brain. Postgrad Med J 82:84-8. Available from: https://www.ncbi.nlm.nih.gov/pubmed/16461469. Accessed 9 Mar 2020

30. Bouzat P, Sala N, Payen J-F, Oddo M, Patel H, Menon D, et al. (2013) Beyond intracranial pressure: optimization of cerebral blood flow, oxygen, and substrate delivery after traumatic brain injury. Ann Intensive Care. Springer Paris 3:23.
Available from: https://annalsofintensivecare.springeropen.com/ articles/10.1186/2110-5820-3-23 Accessed 2016 Aug 11.

31. Kim K-H. (2009) Predictors for functional recovery and mortality of surgically treated traumatic acute subdural hematomas in 256 patients. J Korean Neurosurg Soc. 45:143-50. Available from: https://www.ncbi.nlm.nih.gov/pubmed/19352475. Accessed 9 Mar 2020 